\title{
MRI EVALUATION OF NECK PAIN
}

\author{
Islam $\mathrm{MK}^{1}$, Alam $\mathrm{SZ}^{2}$, Rahman $\mathrm{MS}^{3}$, Akter $\mathrm{A}^{4}$
}

\begin{abstract}
Patients with neck pain both acute and chronic of various aetiologies are commonly found throughout the world for years. Magnetic Resonance Imaging (MRI) is an excellent imaging modality for demonstration of aetiology of neck pain. Degenerative changes, infective processes, neoplastic processes, mechanical injuries and congenital disorders of the spine can be detected by MRI without any hazards. This prospective study of neck pain was done in Radiology and Imaging department of Bangabandhu Sheikh Mujib Medical University and Combined Military Hospital, Dhaka on 60 cases of both sexes reported during the period, February 2006 to September 2006. The aim of the study was to find out the role of MRI in diagnosis and evaluation of chronic and acute neck pain. Out of 60 cases, 51 cases were with cervical spondylotic changes, 2 cases were with spinal trauma, 2 cases were space occupying lesion (SOL) in spinal cord, 1 case was SOL in vertebra, 1 case was soft tissue mass in neck. Only 2 cases showed normal MRI findings. The youngest patient was a fourteen year old male and oldest one was 75 years old male person. Highest incidence was in the 5th decade numbering $20(33.3 \%)$. MRI is non-invasive, non hazardous method and have very few contraindications. Though MRI is relatively expensive and still then it is good considering the diagnostic accuracy and cost effectiveness.
\end{abstract}

Key Words: MRI evaluation, Neck pain.

\section{Introduction}

A revolutionary change in the field of radiology and imaging has occured following advent of "Magnetic Resonance Imaging (MRI)". Due to high sensitivity of MRI abnormalities are often detected in the early stage of disease.MRI reveals disc herniation causing neck pain and myelopathy ${ }^{1}$. MR imaging of the cervical spine in traumatic cases of neck pain provide information that aid in the diagnosis and management of patients with unilateral locked facets of the cervical spine ${ }^{2}$.

\section{Materials and Methods}

This study of 60 cases of neck pain was done at the Radiology and Imaging department of Bangabandhu Sheikh Mujib Medical University (BSMMU) and Combined Military Hospital (CMH), Dhaka with the

cooperation of the neuromedicine and neurosurgery departments of BSMMU and CMH, Dhaka.

Patients, both admitted and outdoor, included in this study had neck pain, both acute and chronic. Presenting signs and symptoms were analyzed and recorded on a prescribed form irrespective of age, sex, region, race, profession and social status. Plain X-ray and subsequently MRI of cervical spine region were done. MRI findings were evaluated and recorded on tabulated formats.

\section{Results}

The age incidence varied from 10 to 80 years. The youngest patient was a fourteen year old male and oldest one was 75 yrs old male person. Highest incidence was in the 5 th decade numbering $20(33.3 \%)$. The incidence in the 6 th decade were $14(23.3 \%)$ and in the 4 th decade was $12(20 \%)$ (table-I).

Male and female ratio was 3:1. Most of the patients underwent MRI for neck pain were service holder (40\%) and businessmen $(26.66 \%)$ (table-II). The nature of the diseases was shown in table-IV. Out of 60 cases 51 cases were with cervical spondylotic changes, 2 cases were with spinal trauma and 2 cases were space occupying lesion (SOL) in spinal cord. Only 2 cases showed normal MRI findings. Most of the patients underwent MRI of cervical region for neck pain showed central or para central stenosis (table-V). In this study the most commonly involved disc was between $\mathrm{C}_{5}$ and $\mathrm{C}_{6}$ and

Table I : Frequency of neck pain in different age group $(\mathrm{n}=60)$.

\begin{tabular}{|c|c|c|}
\hline Age & Number of Patients & Percentage \\
\hline $01-20$ & 02 & 03.3 \\
\hline $20-30$ & 05 & 08.3 \\
\hline $30-40$ & 12 & 20.0 \\
\hline $40-50$ & 20 & 33.3 \\
\hline $50-60$ & 14 & 23.3 \\
\hline $60-70$ & 06 & 10.0 \\
\hline $70-80$ & 01 & 01.7 \\
\hline
\end{tabular}

Table-II: Occupational distribution of study population $(\mathrm{n}=60)$.

\begin{tabular}{|l|c|c|}
\hline Occupation & No of Patient & Percentage \\
\hline Service & 24 & 40.0 \\
\hline Businessman & 16 & 26.7 \\
\hline House Wife & 11 & 18.3 \\
\hline Student & 05 & 08.3 \\
\hline Cultivation & 04 & 06.7 \\
\hline
\end{tabular}

1. Maj Md Khairul Islam, Specialist in Radiology and Imaging, CMH Bogra, 2. Lt Col Syed Zoherul Alam, Classified Specialist in Radiology and Imaging, CMH Dhaka, 3. Col Md Sayedur Rahman, Classified Specialist in Radiology and Imaging, CMH Ghatail, 4. Maj Afroza Akhter, Specialist in Radiology and Imaging, CMH Dhaka.

JAFMC Bangladesh. Vol 5, No 1 (June) 2009 
between $\mathrm{C}_{2}$ to $\mathrm{T}_{1}$. All discs were found to be involved in different frequencies (table-VI).

Table-III : Distribution of cases as per clinical feature $(n=60)$.

\begin{tabular}{|l|c|c|}
\hline Symptoms/sign & No of Patient & Percentage \\
\hline Neck pain & 60 & 100.0 \\
\hline Vertigo & 01 & 01.7 \\
\hline Right brachyalgia & 08 & 13.3 \\
\hline Left brachyalgia & 11 & 18.3 \\
\hline Muscle wasting & 03 & 05.0 \\
\hline Quadriparesis & 01 & 01.7 \\
\hline Restricted movement of neck & 08 & 13.3 \\
\hline Tingling & 10 & 16.7 \\
\hline Numbness & 10 & 16.7 \\
\hline
\end{tabular}

Table-IV: MRI analysis of nature of disease of the spine $(n=60)$.

\begin{tabular}{|l|c|c|c|c|}
\hline Findings & Male & Female & Total & Percentage \\
\hline Normal findings & 02 & 00 & 02 & 03.3 \\
\hline Positive findings & 42 & 16 & 58 & 96.7 \\
\hline Degenerative cervical spondylosis & 36 & 15 & 51 & 85.0 \\
\hline Traumatic condition & 02 & 00 & 02 & 03.3 \\
\hline SOL in spinal cord & 02 & 00 & 02 & 03.3 \\
\hline SOL in vertebra & 00 & 01 & 01 & 01.7 \\
\hline SOL in vertebral canal & 01 & 00 & 01 & 01.7 \\
\hline Soft tissue mass in neck & 01 & 00 & 01 & 01.7 \\
\hline
\end{tabular}

Table-V : Analysis of disc lesions in cervical region by MRI $(\mathrm{n}=60)$.

\begin{tabular}{|l|c|c|}
\hline Disc lesion & $\begin{array}{c}\text { Number of } \\
\text { Patients }\end{array}$ & Percentage \\
\hline Disc desiccation & 40 & 66.7 \\
\hline Disc bulge & 45 & 75.0 \\
\hline Disc Protrusion & 08 & 13.3 \\
\hline Disc extrusion & 04 & 06.7 \\
\hline Central stenosis & 30 & 50.0 \\
\hline Left Para central stenosis & 17 & 28.3 \\
\hline Right Para central stenosis & 14 & 23.3 \\
\hline Bilateral foraminal narrowing & 30 & 50.0 \\
\hline Left foraminal narrowing & 35 & 58.3 \\
\hline Right foraminal narrowing & 28 & 46.7 \\
\hline Pressure effect over the theca & 50 & 83.3 \\
\hline
\end{tabular}

Table-VI : Distribution of intervertebral disc lesions in the cervical region by MRI $(n=60)$.

\begin{tabular}{|l|c|c|}
\hline Intervertebral disc involved & $\begin{array}{c}\text { Number of } \\
\text { Patients }\end{array}$ & Percentage \\
\hline Disc in between C2 and C3 & 03 & 05.0 \\
\hline Disc in between C3 and C4 & 15 & 25.0 \\
\hline Disc in between C4 and C5 & 30 & 50.0 \\
\hline Disc in between C5 and C6 & 47 & 78.3 \\
\hline Disc in between C6 and C7 & 38 & 63.3 \\
\hline Disc in between C7 and T1 & 02 & 03.3 \\
\hline
\end{tabular}

\section{Discussion}

Several recent development came to enrich clinical acumen and technical modalities and expertise, among which plain x-ray is the most popular one used in diagnosis of neck pain. On the other hand MRI is the gold standard modality for diagnosis of neck pathology ${ }^{3}$.
Analysis of clinical features of 60 patients reveals that most of the patients had radiating pain to the upper limbs. Other features included tingling (16.67\%), numbness $(16.7 \%)$, restricted movement of neck $(13.3 \%)$, muscle wasting (5\%), vertigo (1.7\%) and quadriparesis (1.7\%). Patient with neck pain may have associated other symptoms of radiculopathy and myelopathy ${ }^{4}$.

Almost all the patients $(96.66 \%)$ underwent MRI of cervical spine for neck pain showed lesions. Only 2 patients among 60 had no lesion. Out of 60 cases 51 had cervical spondylosis.

In one male patient presented with neck pain and subsequent quadriparesis, MRI of cervical spine showed metastasis in $\mathrm{C}_{5}$ and $\mathrm{C}_{6}$ vertebra from thyroid carcinoma with soft tissue extension of the mass compressing the spinal cord. Simultaneous metastases to the bone and soft tissue are extremely rare . $^{5}$

MRI offers new opportunity for early diagnosis of myelopathy owing to osteoarthritis or rheumatoid arthritis, vertebral osteomyelitis and metastatic involvement of cervical vertebra ${ }^{6}$.

Of the traumatic 2 cases of present series, MRI findings in one showed compression fracture of $\mathrm{C}_{5}$ and $\mathrm{C}_{6}$ vertebra with degenerative changes and in another there was fracture of anterior part of the body of $\mathrm{C}_{7}$ vertebra with compression of spinal cord by the postero superior part of the body of $\mathrm{C}_{7}$ vertebra. Goradia et al observed that MRI is highly sensitive for injury to vertebra, disk, posterior longitudinal ligament and interspinous soft tissues, but less sensitive for injury to anterior longitudinal ligament and ligamentum flavum ${ }^{7}$.

Analysis of distribution of intervertebral disc lesion in cervical region by MRI showed that disc lesions were common in $\mathrm{C}_{5-6}$ and $\mathrm{C}_{6-7}$ and uncommon in $\mathrm{C}_{2-3}$ and $\mathrm{C}_{7^{-}}-\mathrm{T}_{1}$ levels. In another study of 150 cases of cervical spondylosis Ahn et al observed most common disc lesion in $\mathrm{C}_{5-6}$ and $\mathrm{C}_{6-7}$ levels ${ }^{8}$.

MRI is very helpful in evaluation of the spinal tumours, compression as well as involvement of bone and soft tissues and those can be clearly delineated ${ }^{9}$. One further advantage of MRI is the ability to visualize extensive regions of the spine in a non-invasive way ${ }^{10}$.

Tuberculosis of the spine is not uncommon in Bangladesh. Patient with tubercular spondylitis may present with backache and neck pain with neurological deficit due to vertebral body destruction and protrusion into the spinal canal causing compression of the spinal $\operatorname{cord}^{11}$. In a study of 100 cases of spinal tuberculosis $23 \%$ cases found in lower thoracic spine, $69 \%$ in thoracolumbar, 5\% in cervical and 3\% in upper dorsal spine region ${ }^{12}$. MRI should be considered to be the imaging modality of choice for patient suspected to have tuberculous spinal infection ${ }^{13}$. In this series no tuberculosis case was identified. This indicates that tuberculosis less commonly involves neck region.

MRI has exceeded original expectations and it now stands as the preferred imaging modality for evaluation of neck pain. The contrast, sensitivity and multiplanner imaging 
capability of MRI provide an unique advantage. With a combination of imaging planes and pulse sequences, the anatomy of the discovertebral complex, spinal cord and dural sac are clearly depicted ${ }^{14}$. In this study, MRI showed vertebral lesion, spinal cord tumor, soft tissue mass in neck and pressure effect over the theca due to spondylotic changes and were accountable to neck pain.

\section{Conclusion}

Considering the diagnostic accuracy, non-invasiveness, non hazardous and have very few contraindications of the procedure and better visualization of the lesions in different sections, MRI should be the pre and post operative diagnostic modality of the spine. The only disadvantage of MRI is its high cost, still then it is good considering the diagnostic accuracy and cost effectiveness.

\section{References}

1. Herkowitz HN, Kleinschmidt L. Surgical management of cervical soft disc herniation. A comparison between anterior and posterior approach of spine. J Belgi Radiol 1999 Oct; 15 (10): 1026-30.

2. Shapiro S, Synder W, Kaufman K, et al. Outcome of 51 cases of unilateral locked cervical facets. J Neuro Surg 1999 Jul ; 91: 19-24.
3. Sarani B, Waring S, Sonnad S et al. Magnetic resonance imaging is a useful adjunct in the evaluation cervical spine of injured patients. J Trauma 2007 Sep;63(3):637-40.

4. Kaiser MG. Multilevel cervical spondylosis. Neurosurg Clin N Am 2006 Jul; 17 (3): 263-75.

5. Rodrigues G, Ghosh A. Synchronous bony and soft tissue metastases from carcinoma of the thyroid. J Korean Med Sci 2003 Dec; 18 (6):914-6. 6. Grossman C, Barrie. Magnetic Resonance Imaging and Computed Tomography of the head and spine. Neuroradiology 2001Jan ; 717-734.

7. Goradia D, linnau KF, Cohen WA et al. Correlation of MR Imaging findings with intraoperative findings after cervical spinal trauma.American Journal of Neuroradiology 2007 Feb;28(5):209-78.

8. Ahn Nu, Ahn UM, Ipsen B, et. al. Mechanical neck pain and cervicogenic headache. Neurosurgery. 2007 Jan; 60 (1 Supp1 1):S21-7.

9. De Beuckleer L, Vanden Hauwe L, Bracke P et al. Imaging of primary tumors and tumor like conditions of spine. J-Belge-Radiol 2001Feb ; 80(1): 21-5.

10. Patel H, Boaz J.C, Phillips J.P, Garg B.P et al. Spontaneous spinal epidural hematoma in children. Pediatr-Neurol 2001 Oct ; 19(4): 302-7.

11. Grossman CB. Magnetic Resonance Imaging and computed tomography of the Head and spine. 2nd ed.Baltimore: Williams Wilkins Company; 2002. p.637-660.

12. Khorvash F, Javadi AA, Izadi M et al. Spinal tuberculosis: a major public health hazard is Isfahan. Pak J Biol Sci 2007 Oct 1;10 (19):3400-4.

13. Loke TK, Ma HT, Chan CS. Magnetic Resonance Imaging of Tuberculous spinal infecltion. Australus Radiol 2001Feb ; 46: 7-12.

14. Modic MT, Masaryk TJ, Ross JS et al. Imaging of degenerative disc disease. Radiology 2003; 168: 177-186. 